\title{
DJ STENT: FORGOTTEN FOR FOURTEEN YEARS
}

\author{
S. S. Karbhari' ${ }^{1}$, Akshay Kriplani² ${ }^{2}$ R. B. Dhaded $^{3}$
}

\section{HOW TO CITE THIS ARTICLE:}

S. S. Karbhari, Akshay Kriplani, R. B. Dhaded. "DJ Stent: Forgotten for Fourteen Years". Journal of Evolution of Medical and Dental Sciences 2015; Vol. 4, Issue 26, March 30; Page: 4527-4530,

DOI: $10.14260 /$ jemds/2015/654

\begin{abstract}
Ureteral stents play a major role in a wide range of situations where urinary drainage is needed, but long standing stents lead to a variety of complications. Here we report a case of a 7 months old girl was stented with a double J stent for bilateral urethral calculi. 14 years later surgeons discover a stent fragment in left ureter with associated complications including staghorn calculi formation. An Open nephrolithotomy with stent residue removal was done.
\end{abstract}

KEYWORDS: Double J stent, Urinary Tract Infection. Staghorn Calculi, Nephrolithotomy.

INTRODUCTION: The Double-J Ureteral Stent or Pigtail Stent has been an important tool in the urological surgical practice. It is a catheter or tube placed within the ureteral lumen in a retrograde or antegrade fashion in order to maintain its patency, with a self-retaining capability due to a double coil design at proximal and distal ends that work to securely anchor the stent in the upper urinary tract (renal pelvis and upper calyx) and the bladder.[1] It thus plays a major role in a wide range of situations where urinary drainage is needed. But long standing indwelling catheters are known to cause complications.[1,2]

Here we report a case of a 7 months old girl was stented with a double J stent for bilateral urethral calculi. 14 years later surgeons discover a stent fragment in left ureter with associated complications including staghorn calculi formation. An Open nephrolithotomy with stent residue removal was done.

CASEREPORT: 14 yrs old female, belonging to low socio-economic status, presents with pain in lower back since 2 months, burning micturition since 2 months, increased frequency of maturation since 2 month, fever since 1 week. No history of hematuria.

Past history- When the patient was 7 months old she had history of urinary retention with abdominal distension. Patient was diagnosed with bilateral ureteral calculi and underwent bilateral endoscopic lithotripsy and double 'J' stenting.

Over the years patient kept complaining of short transient episodes of white discharge and occasional hematuria and burning micturition, which resolved spontaneously without any treatment.10 months back, patient gives history of passing a tube-like structure in urine but was again ignored.

No significant history of receiving any other medical or surgical treatment.

2 months back patient started experiencing bilateral lower back pain, non-radiating, colicky in type, associated with burning maturation when she consulted a doctor and was diagnosed with a 'forgotten' right sided in-situ double 'J' stent (inserted when the patient was 7 months old) with a remnant of the fractured stent on the left side (the remaining half of the stent had passed in the urine 10 months back) with multiple staghorn calculi in the left pelvis. (Figure 1)

The now treating doctor cystoscopically removed the right sided stent and the patient was discharged. 


\section{CASE REPORT}

The patient presented to our hospital with the similar set of complaints with the left sided stent residue with multiple staghorn calculi in-situ. (Figure 2-3)

All blood investigations including the renal function test were normal. Urine examination revealed 10-12 pus cells with 10-12 RBCs and a growth of E. coli. The patient was posted for an open nephropyelolithotomy with the stent residue removal. The patient improved post-operatively with an uneventful postoperative course.

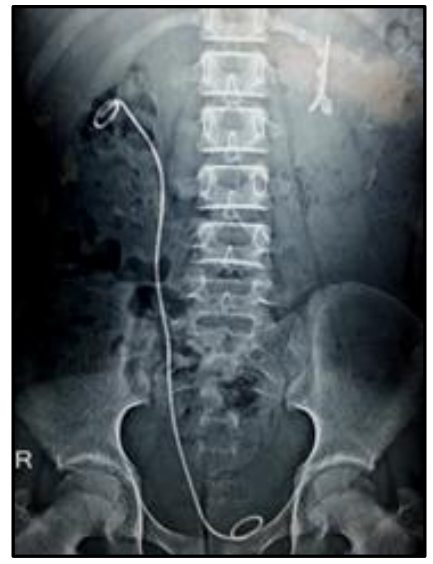

\section{Figure 1: Right DJ stent in situ with left} fragmented segment with Staghorn calculi
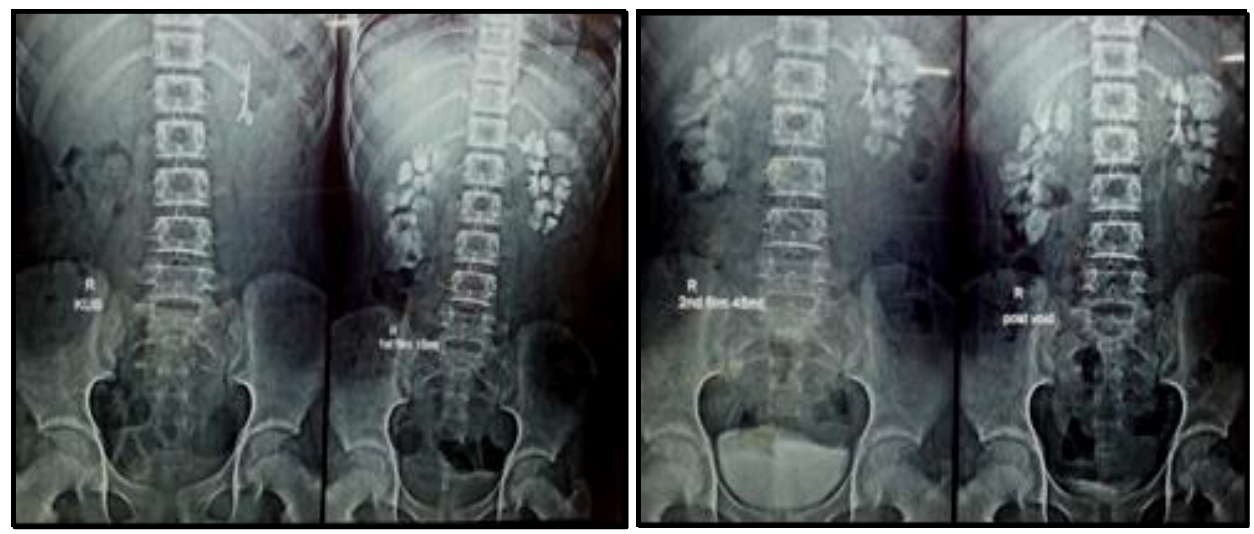

Fig. 2 \& 3: X-ray KUB and IVP

DISCUSSION: Ureteral stents play a major role in a wide range of situations where urinary drainage is needed (Table 1),[1] but long standing stents lead to a variety of complications. These complications may be of minor nature such as hematuria, dysuria, frequency, low back ache and suprapubic pain or may be more major such as vesicoureteric reflux, migration, encrustation, urinary tract infection (UTI), stent fracture and secondary vesical calculus formation.[2,3] Cases of fatality have even been reported in cases of indwelling stents.[2,4]

In order to avoid such complications, the ideal time for DJ stent removal or replacement is considered between 2 and 4 months.[5,6]

For early detection and to contain such delayed complications a computerized tracking program for removal of stents was proposed by Atheret al[7] and Joshi et al[8] also objectively evaluated the UTI symptomatology associated with indwelling stents using validated questionnaires 
(International Prostatic Symptoms Score - IPSS, International Continence Society male questionnaire, Quality of Life questionnaires, and the Bristol Female Lower Urinary Tract Symptoms questionnaire BFLUTS). The Ureteral Stent Symptom Questionnaire (USSQ) consists of 38 items examining 6 sections: pain, voiding symptoms, work performance, sexual matters, overall general health, and additional problems. ${ }^{[8]}$

Ashutosh Niranjan et al,[9] in their article 'Enigma of Forgotten Double J Stent', reported a 'forgotten' stent in the ureter for 12 years. Prior to their citing, the available literature showed that DJ stent had been missed for a maximum of eight years and in most cases, the stent had fragmented spontaneously.[9]

But the present case is a rare presentation of a 'forgotten' stent for almost 14 years, with associated complications like stent fragmentation, UTI and subsequent development of bilateral staghorn calculi.

Ringel A. et al[10] observed that the total complication rate in 110 stented kidneys where the stents were kept in situ for different periods, was up to $32.7 \%$ and in $8.2 \%$ of the cases, the stents had migrated.

In another study, Damiano R et al[11] observed flank pain in $25.3 \%$, encrustations in $21.6 \%$, irritative bladder symptoms in $18.8 \%$, hematuria in $18.1 \%$, fever more than $104^{\circ} \mathrm{F}$ in $12.3 \%$ and stent migration in $9.5 \%$ of the patients. They also reported that morbidity and complications were minimal when the stent was left in situ for less than three months, but longer duration of stent retention was associated with increased frequency of encrustations, infections, calculus formation and obstruction of the stented tract.

Hao P et al[12] evaluated 2685 cases of DJ stent for different nephroureteric conditions and concluded that these stents are a safe and useful adjunct for both endoscopic and open procedures, if it was kept in situ for less than 28 days.

CONCLUSION: Careful monitoring of patients could exclude any possibility of a stent being forgotten at all. Although endourology has simplified the management of forgotten indwelling stents, the best solution remains prevention.

\begin{tabular}{|c|c|c|}
\hline Urgent & Safety Related & Relative \\
\hline Obstructive pyelonephritis & Ureteral edema & Stone burden $>2 \mathrm{~cm}$ before SWL \\
\hline Intolerable acute renal colic & Ureteral perforation & Pregnancy \\
\hline $\begin{array}{c}\text { Renal failure secondary } \\
\text { to ureteral obstruction }\end{array}$ & $\begin{array}{c}\text { Previous history } \\
\text { of renal failure }\end{array}$ & $\begin{array}{c}\text { Long-standing } \\
\text { impacted stone }\end{array}$ \\
\hline & Solitary kidney & $\begin{array}{c}\text { Recent history of urinary tract } \\
\text { infection or sepsis }\end{array}$ \\
\hline & Transplant kidney & $\begin{array}{c}\text { Passive dilation of ureteral } \\
\text { orifice and ureter }\end{array}$ \\
\hline & & $\begin{array}{c}\text { Prolonged endoscopic } \\
\text { operative time }\end{array}$ \\
\hline & & $\begin{array}{c}\text { Patients with imminent } \\
\text { Post-operative plans (2nd look) }\end{array}$ \\
\hline \multicolumn{2}{|c}{ Table 1: Current indications for stent replacement } \\
\hline
\end{tabular}




\section{REFERENCES:}

1. Ricardo Miyaoka, Manoj Monga; 'Ureteral stent discomfort: Etiology and management'; Indian Journal of Urology, October-December 2009. 455-450.

2. Aditi S. Agrawal, Siddharth Rao, Dilip O. Gupta; 'DJ stent: Boon or curse', Journal of Mahatma Gandhi Institute of Medical Sciences; September 2013; Issue 2; Vol. 18.

3. Khader K el; 'Complications of double J ureteral stents'; J Urol (Paris) 1996; 102:173-5.

4. Monga M, Klein E, Castañeda-Zúñiga WR, Thomas R; 'The forgotten indwelling ureteral stent: A urological dilemma'; J Urol 1995; 153:1817-9.

5. Lam JS, Gupta M; 'Tips and tricks for the management of retained ureteral stents'; J. Endourol 2002; 16:733-41.

6. Borboroglu PG, Kane CJ; 'Current management of severely encrusted ureteral stents with a large associated stone burden'; J Urol 2000;164:648-50.

7. Ather $\mathrm{MH}$, Talati J, Biyabani R; 'Physician responsibility for removal of implants: The case for a computerized program for tracking overdue double-J stents'; Tech Urol 2000; 6:189-92.

8. Joshi HB, Stainthorpe A, Keeley FX, Macdonagh R, Timoney AG; 'Indwelling Ureteral Stents: Evaluation of Quality of Life to Aid Outcome Analysis'; J Endourol 2001; 15:151-4.

9. Ashutosh Niranjan et al; 'Enigma of Forgotten Double J Stent'; Saudi J Kidney Dis Transpl 2010; 21 (1):157-159.

10. Ringel A, Richter S, Shalev M, Nissenkorn I; 'Late complications of ureteral stents'; EurUrol 2000;38(1):41-4.

11. Damiano R, Oliva A, Esposito C, De Sio M, Autorino R, D'Armiento M.; 'Early and late complications of double pigtail ureteral stent'; UrolInt 2002; 69 (2):136-40.

12. Hao P, Li W, Song C, Yan J, Song B, Li I;'Clinical evaluation of double pigtail stent in patients with upper urinary tract diseases: report of 2685 cases'; J Endourol 2008;22(1): 65-70.

\section{AUTHORS:}

1. S. S. Karbhari

2. Akshay Kriplani

3. R. B. Dhaded

\section{PARTICULARS OF CONTRIBUTORS:}

1. Associate Professor, Department of Surgery, Mahadevappa Rampure Medical College, Gulbarga.

2. Post Graduate, Department of Surgery, Mahadevappa Rampure Medical College, Gulbarga.

3. Professor and HOD, Department of Surgery, Mahadevappa Rampure Medical College, Gulbarga.

NAME ADDRESS EMAIL ID OF THE CORRESPONDING AUTHOR:

Dr. Akshay Kriplani, Room No. 201, PG Boys Hostel, Basaveshwar Teaching and General Hospital, Gulbarga.

E-mail: akshaykriplani@gmail.com

Date of Submission: 19/12/2014.

Date of Peer Review: 20/12/2014.

Date of Acceptance: 19/03/2015.

Date of Publishing: 30/03/2015.

FINANCIAL OR OTHER

COMPETING INTERESTS: None 